\title{
X-ray Photoelectron Spectroscopy Analysis of Anodic Oxide Film on Titanium
}

\author{
Toshio SHIBATA* and Yao-Can ZHU
}

Received January 27, 1993 ; Accepted March 25, 1993

\section{INTRODUCTION}

Titanium is one of the materials exhibiting high corrosion resistance by forming a protective oxide film. Investigation on the composition and thickness of oxide film is of importance in understanding the protective mechanism of the oxide film. There have been reports ${ }^{1-3)}$ that the oxide film on titanium was analyzed by $\mathrm{X}$-ray Photoelectron Spectroscopy(XPS), but, the quantitative XPS analysis on the composition and film thickness of the oxide film anodically formed on titanium has scarcely been done. It has been confirmed that the mixed-valent oxides of titanium $\left(\mathrm{TiO}_{2}, \mathrm{Ti}_{2} \mathrm{O}_{3}\right.$ and $\left.\mathrm{TiO}\right)$ coexist in the electrochemical oxidation film ${ }^{1-3)}$.

In this work, we have used the quantitative XPS analysis to estimate the thickness of the oxide film anodically formed on titanium, and measure the distribution of the multiple oxidation states of titanium in the film.

\section{EXPERIMENTAL}

Working electrodes were prepared from a commercially pure titanium sheet containing some minor impurities ( O: 470; Fe: 350; C: 5; N: 33 and $\mathrm{H}$ : $18 \mathrm{ppm}$ ). Specimens were mechanically polished with $2 / 0,4 / 0,6 / 0$ and finally 2000 emery paper, spotted in pure titanium wires (diameter: $0.5 \mathrm{~mm}$ ), then rinsed with distilled water. The anodic oxide films on titanium were formed potentiostatically at $303 \mathrm{~K}$ at different formation potentials from 1 to $9 \mathrm{~V}$ for $1 \mathrm{~h}$ in 0.5 $\mathrm{M} \mathrm{H}_{2} \mathrm{SO}_{4}$ solution. The effect of temperature was examined at $1 \mathrm{~V}$ with changing temperature from 303 to $353 \mathrm{~K}$. The solutions were constantly

Department of Materials Science and Processing, Faculty of Engineering, Osaka University (2-1 Yamadaoka, Suita, Osaka 565 JAPAN)

Key Words: x-ray photoelectron spectroscopy, oxide film, composition, depth profile deaerated with purified nitrogen. All potentials are referred to an $\mathrm{Ag} / \mathrm{AgCl}(3.3 \mathrm{M} \mathrm{KCl})$ electrode.

After $1 \mathrm{~h}$ film formation, the samples were removed from the solution, rinsed with distilled water and dried with filter paper, then transferred to the analyzer as rapidly as possible for the XPS analysis. All XPS measurements were carried out with RDK XPS-7000 Spectrometer using Al Ka $(1486.6 \mathrm{eV})$ radiation. Sputtering was performed with an argon ion gun at $600 \mathrm{~V}$ and $20 \mu \mathrm{A}$. The binding energies were calibrated with the following line positions: $\mathrm{Au}\left(4 \mathrm{f}_{7 / 2}\right)$ at $83.8 \mathrm{eV}$ and $\mathrm{C}(1 \mathrm{~s})$ at $285.0 \mathrm{eV}$.

\section{RESULTS AND DISCUSSION}

Oxide film composition.- The $\mathrm{Ti}\left(2 \mathrm{p}_{3 / 2,1 / 2}\right)$ spectra at various sputtering times for the sample pretreated at $3.0 \mathrm{~V}$ at $303 \mathrm{~K}$ are shown in Fig.1. The binding energy of the $\operatorname{Ti}\left(2 \mathrm{p}_{3 / 2}\right)$ signals from

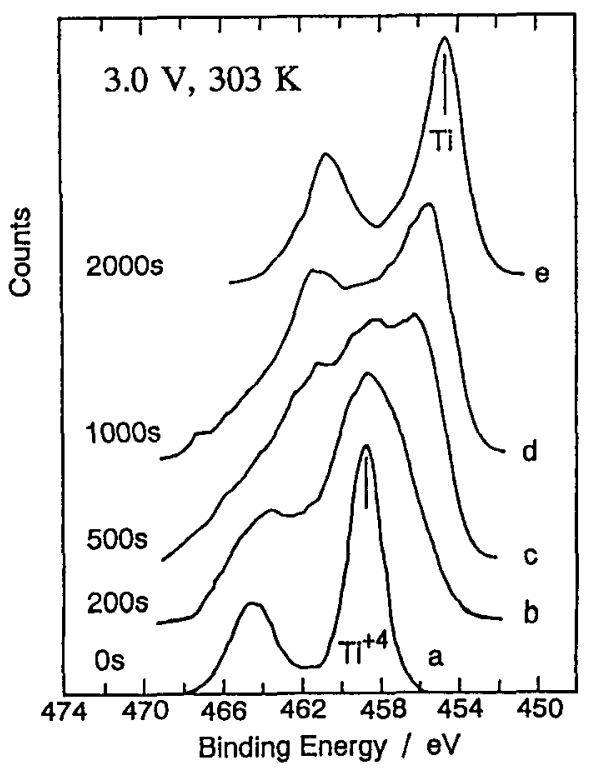

Fig. 1. The $\operatorname{Ti}\left(2 \mathrm{p}_{1 / 2}, 3 / 2\right)$ spectra at various sputtering times. 


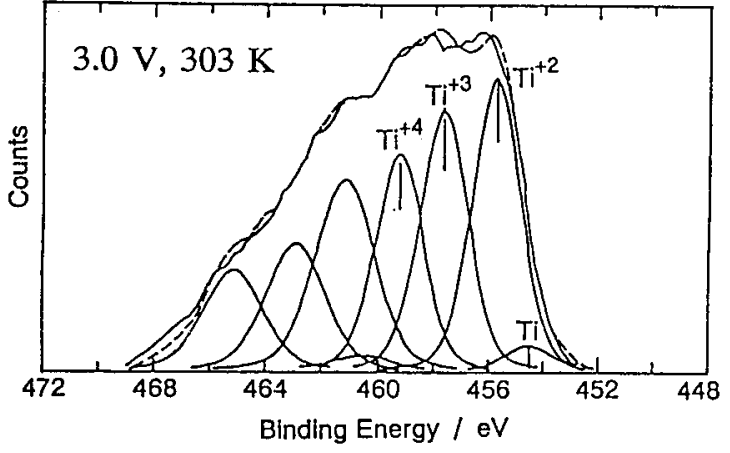

Fig. 2. The deconvoluted $\operatorname{Ti}\left(2 \mathrm{p}_{1 / 2,3 / 2}\right)$ spectra of (c) in Fig. 1.

the outmost surface film was found to be 459.20 $\mathrm{eV}$. This value is consistent with that reported for $\mathrm{TiO}_{2}{ }^{2,4)}$. The spectra change with sputtering time from (a) to (e) indicated in Fig.1. The peak at $454.6 \mathrm{eV}$ which is attributed to metallic titanium has completely appeared after the sputtering time of 2000s. Figure 2 shows the deconvoluted $\operatorname{Ti}\left(2 \mathrm{p}_{1 / 2,3 / 2}\right)$ spectra which are equivalent to Fig.1c. Deconvolution of the spectra was carried out by a Gaussian distribution simulation with binding energies and full widths at half maximum(HWHM) of each titanium component referenced to that of standard titanium materials. The $\mathrm{Ti}\left(2 \mathrm{p}_{3 / 2}\right)$ binding energies for $\mathrm{TiO}_{2}, \mathrm{Ti}_{2} \mathrm{O}_{3}$, $\mathrm{TiO}$ and $\mathrm{Ti}$ are $459.2,457.5,455.8$ and 454.6 $\mathrm{eV}^{2)}$, respectively. The HWHM is $2.0 \mathrm{eV}$ for each titanium component ${ }^{2)}$. All these spectra indicated in Fig. 1 and 2 are shown after smoothing and background subtraction based on Shirley's method. As shown in Fig.2, it can be seen that the multiple oxidation state ions of titanium exist in anodic surface film. The detected $O(1 \mathrm{~s})$ signals from the outmost surface film, which are not shown here, are mainly due to the $\mathrm{M}-\mathrm{O}$ of $\mathrm{TiO}_{2}$ $(530.5 \mathrm{eV})$. Another small signals of a higher binding energy $(531.7 \mathrm{eV})$ were detected, suggesting the presence of absorbed water or $\mathrm{OH}$ in the oxide film as reported by other researchers ${ }^{2,3)}$.

Depth profiles of oxide film.- The $\mathrm{C}(1 \mathrm{~s})$ signals were detected but very weak, so that effect of the absorbed carbon contaminant layer was neglected. The sample pretreated was assumed to consist of the oxide overlayer and metallic substrate. Then

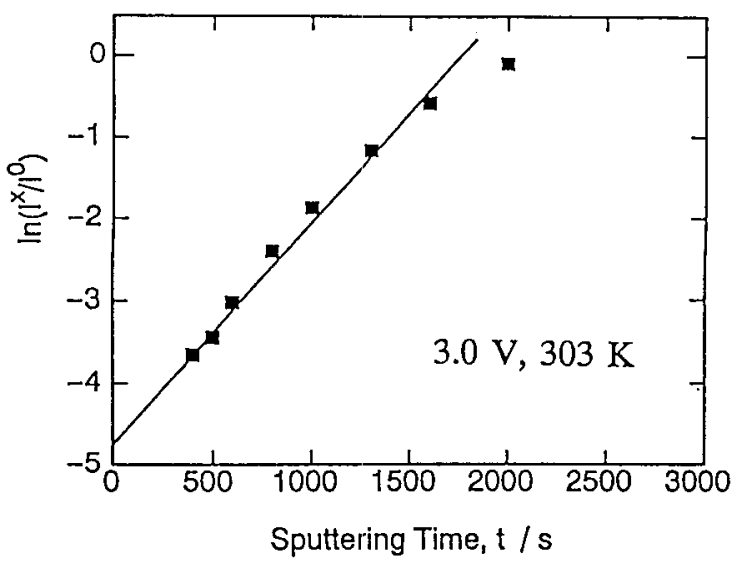

Fig. 3. $\ln \left(\mathrm{I}^{\mathrm{X}} / \mathrm{I}^{0}\right)$ vs. $t$ plot for the sample pretreated at $3.0 \mathrm{~V}$ at $303 \mathrm{~K}$.

the intensity of the $\operatorname{Ti}\left(2 \mathrm{p}_{3 / 2}\right)$ photoelectrons from the substrate can be described by the following equation $^{5)}$

$$
I^{x}=I^{0} \exp (-x / \lambda \sin \theta)
$$

where $\mathrm{x}$ is the thickness of the oxide overlayer, $\mathrm{I}^{0}$ is the intensity emitted by the titanium substrate at the oxide overlayer/substrate interface, $\theta$ is the take off angle of photoelectron $\left(=90^{\circ}\right)$, and $\lambda$ is the photoelectron escape depth which is equal to $18.05 \AA$ calculated from the electron kinetic energy according to Seah and Dench ${ }^{6)}$. If the sputtering rate, $\mathrm{r}=-\mathrm{dx} / \mathrm{dt}$, is constant, the residual thickness, $x$, of the oxide after $t$ sputtering times can be given by

$$
\mathrm{x}=\mathrm{d}-\mathrm{rt}
$$

where $\mathrm{d}$ is the original thickness. Combining Eq. (1) and (2) and taking a simple transformation yield the following linear relation

$$
\ln \left(\mathrm{I}^{\mathrm{x}} / \mathrm{I}^{0}\right)=\mathrm{at}-\mathrm{b}
$$

where $a=r / \lambda$ and $b=d / \lambda$.

$\ln \left(\mathrm{I}^{\mathrm{x}} / \mathrm{I}^{0}\right)$ vs. $\mathrm{t}$ plot for the sample pretreated at $3.0 \mathrm{~V}$ and $303 \mathrm{~K}$ is shown in Fig.3. The linear plot in the figure indicates that the sputtering rate is constant, and the film thickness $\mathrm{d}$ can be directly calculated from the intercepted value, $b$. The film thickness derived by this method is plotted as a function of the pretreated potential in 


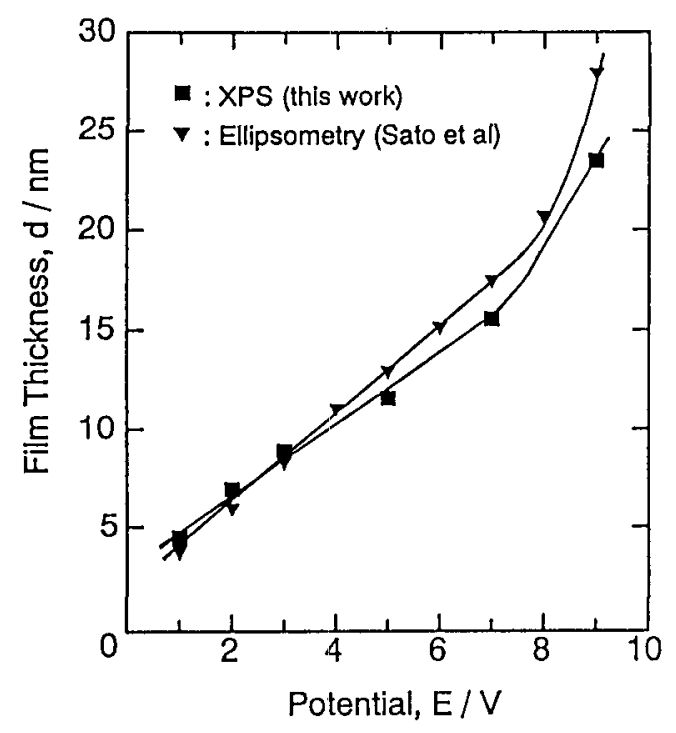

Fig. 4. The film thickness as a function of the pretreated potential.

Fig.4. The film thickness determined by ellipsometry ${ }^{7)}$ is also included in Fig.4. The good agreement between the XPS and ellipsometry data demonstrates that the analysis of the oxide film on titanium by combining ion sputtering and XPS is valid. In addition, the relation of the film thickness determined by this method and temperature is also compared with that determined by using the charge consumed for film formation in Fig. $5^{8)}$. A similar increase in both data of the film thickness can be seen clearly. It is interesting to note that the film thickness changes greatly at ca. $325 \mathrm{~K}$. At this temperature, however, the composition of the oxide film has almost no change as shown later (see Fig. 7), so that the abrubt increase in the film thickness is more likely to be associated with a change of the structure of the film.

As seen from the deconvoluted spectra (see Fig.2), there are three oxidation states of $\mathrm{Ti}^{+4}, \mathrm{Ti}^{+3}$ and $\mathrm{Ti}^{+2}$ in the oxide film. Each concentration of titanium ions as well as oxygen in the anodic oxide film can be obtained from the following equations $^{6)}$

$$
\begin{aligned}
& \mathrm{I}_{\mathrm{ox}, \mathrm{Ti}(+\mathrm{n})}=\mathrm{K}_{\mathrm{ox}, \mathrm{Ti}} \sigma_{\mathrm{ox}, \mathrm{Ti}} \mathrm{C}_{\mathrm{ox}, \mathrm{Ti}(+n)} \lambda_{\mathrm{ox}, \mathrm{Ti}} \\
& {\left[1-\exp \left(-\mathrm{x} / \lambda_{\text {ox }, \mathrm{Ti}}\right)\right]}
\end{aligned}
$$

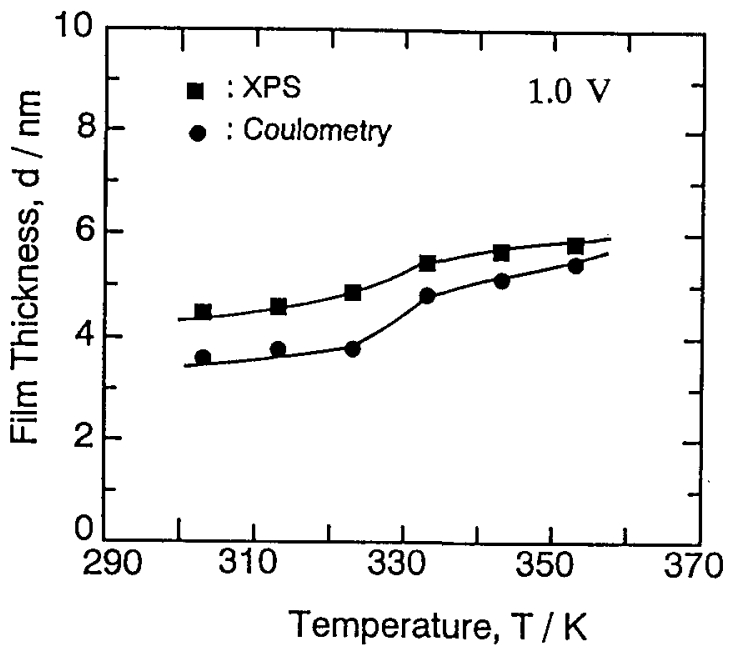

Fig. 5. The relation between the film thickness and temperature.

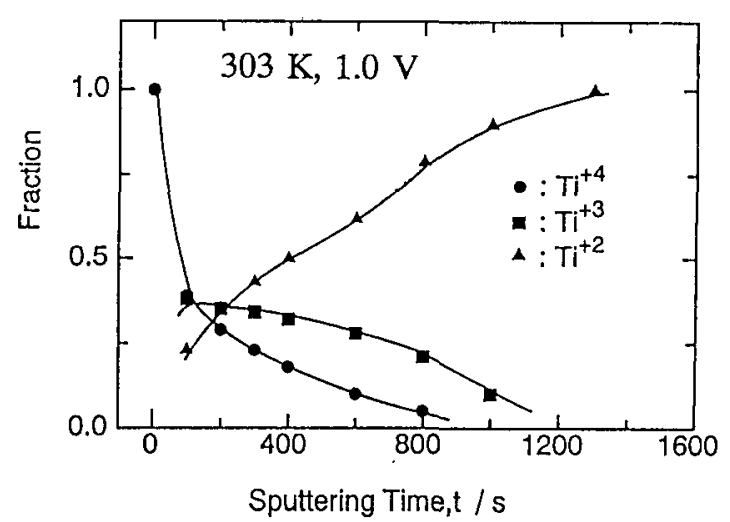

Fig. 6. Change in the fractions of $\mathrm{Ti}^{+4}, \mathrm{Ti}^{+3}$ and $\mathrm{Ti}^{+2}$ in the film against sputtering time.

$$
\begin{aligned}
\mathrm{I}_{\mathrm{ox}, \mathrm{O}}= & \mathrm{K}_{\mathrm{ox}, \mathrm{O}} \sigma_{\mathrm{ox}, \mathrm{O}} \mathrm{C}_{\mathrm{ox}, \mathrm{O}} \lambda_{\mathrm{ox}, \mathrm{O}}[1- \\
& \left.\exp \left(-\mathrm{x} / \lambda_{\mathrm{ox}, \mathrm{O}}\right)\right]
\end{aligned}
$$

where $\mathrm{n}$ is the valence of titanium oxidation state, $\mathrm{K}$ is the spectrometer factor, $\sigma$ is the photoionization cross section, $\mathrm{C}$ is the atom concentration, and the meanings of $\mathrm{x}$ and $\lambda$ are the same as that in Eq.(1). We assumed that $\sigma$ and $\lambda$ for each oxidation state of titanium are the same $(\lambda=18.05)$. $\lambda$ for oxygen is $18.5 \AA^{9}$ ), approximately equal to that for titanium. The 
relative amounts of mixed-valent oxides can be calculated from the intensity of the respective photoelectron signals by using Eq.(4). Figure 6 shows that the fractions of each titanium ion for the sample pretreated at $1.0 \mathrm{~V}$ and at $313 \mathrm{~K}$ vary with sputtering time. During the initial sputtering time of $200 \mathrm{~s}$, the relative amount of $\mathrm{Ti}^{+4}$ in the oxide film decreases rapidly, and at the same time, the small signals of $\mathrm{Ti}^{+3}$ and $\mathrm{Ti}^{+2}$ in the oxide film are detected. With increasing sputtering time, The relative amounts of $\mathrm{Ti}^{+4}$ and $\mathrm{Ti}^{+3}$ in the oxide film decrease gradually, while the fraction of $\mathrm{Ti}^{+2}$ increases.

Combining Eq.(4) and (5) yields the relative atomic ratios of oxygen to titanium $\mathrm{O} / \Sigma \mathrm{M}_{\mathrm{ox}}$ in the oxide film,

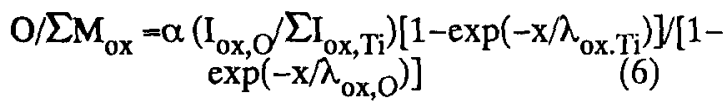

where $I_{o x, O}$ is the intensity of the $O(1 s)$ photoelectrons which originate from the oxide film itself, $\Sigma I_{o x}$. Ti is the sum of the intensity from $\mathrm{Ti}^{+4}, \mathrm{Ti}^{+3}$ and $\mathrm{Ti}^{+2}$ in the oxide film, and $\alpha$ $=\mathrm{K}_{\mathrm{ox}, \mathrm{Ti}} \sigma_{\mathrm{ox}, \mathrm{Ti}} \lambda_{\mathrm{ox}, \mathrm{Ti}} / \mathrm{K}_{\mathrm{ox}, \mathrm{O}} \sigma_{\mathrm{ox}, \mathrm{O}} \lambda_{\mathrm{ox}, \mathrm{O}}$.

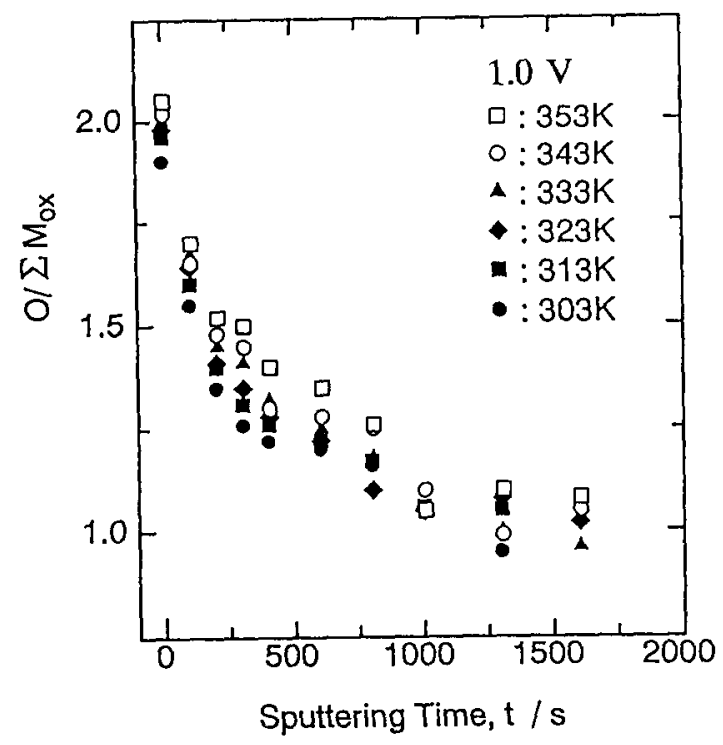

Fig. 7. Change in $\mathrm{O} / \Sigma \mathrm{M}_{\mathrm{ox}}$ in the oxide film against sputtering time.
In order to estimate $\alpha$ in Eq.(6), the sample with thick $\mathrm{TiO}_{2}$ film was prepared, which was formed galvanostatically at $20 \mathrm{~mA}$ until the potential of the electrode reached $65 \mathrm{~V}$. For this sample, $x$ in Eq.(6) can be assumed to be infinite $(=\infty)$, so that $\alpha$ is calculated to be 1.52 from $\alpha=2 /\left(\mathrm{I}_{\mathrm{ox}, \mathrm{O}} / \mathrm{I}_{\mathrm{ox}, \mathrm{Ti}(+4)}\right)$.

The $\mathrm{O} / \Sigma \mathrm{M}_{\mathrm{ox}}$ for the samples pretreated at different temperatures is plotted as a function of sputtering time in Fig.7. $\mathrm{O} / \Sigma \mathrm{M}_{\mathrm{ox}}$ of the outmost surface film for each sample is about 2 which means that $\mathrm{Ti}^{+4}$ exits in the outmost oxide film. With increasing sputtering time, $\mathrm{O} / \Sigma \mathrm{M}_{\mathrm{ox}}$ decreases rapidly, approaching to unity. The mean value of $O / \Sigma M_{o x}$ for each sample was found to be approximately 1.6 which is independent of temperature. By comparing the results from Figs. 6 and 7 , one can find that the outmost surface film is principally composed of $\mathrm{TiO}_{2}$, but beneath this phase the suboxides $\left(\mathrm{Ti}_{2} \mathrm{O}_{3}\right.$ and $\left.\mathrm{TiO}\right)$ coexist with $\mathrm{TiO}_{2}$ which is in agreement with the result obtained by Amstrong .

In conclusion, our quantitative analysis of XPS is suited for the anodic oxide film on titanium. The oxide film can be considered to consist of the outer and inner layer. The outer layer is mainly composed of $\mathrm{TiO}_{2}$, including small $\mathrm{OH}$, and the inner layer may be the mixture of $\mathrm{TiO}_{2}, \mathrm{Ti}_{2} \mathrm{O}_{3}$ and $\mathrm{TiO}$.

\section{REFERENCES}

1) N. R . Armstrong, Surf. Sci., 67, 451(1977).

2) C. N. Sayers and N. R. Armstrong, Surf. Sci., 77, 301(1978).

3) R. K. Quinn and N. R. Armstrong, J. Electrochem. Soc., 125, 1790(1978).

4) G. Nogami, J. Electrochem. Soc., 132, 76(1985).

5) W. Kautek and J. G. Gordon, J. Electrochem. Soc., 137, 2672(1990).

6) M. P. Seah and W. A. Dench, Surf. Anal. Chem., 1, 1(1979).

7) T. Ohtsuka, M. Masuda and N. Sato, J. Electrochem. Soc., 132, 787(1985).

8) T. Shibata and Y.-C. Zhu, to be published.

9) K. Asami and K. Hashimoto, Corros. Sci., 17, 559(1977). 